\title{
A INTENSIFICAÇÃO E PRECARIZAÇÃO DO TRABALHO DOCENTE NOS INSTITUTOS FEDERAIS
}

\author{
INTENSIFICATION AND PRECARIZATION OF TEACHING WORK IN THE \\ FEDERAL INSTITUTES
INTENSIFICACIÓN Y LA PRECARIZACIÓN DEL TRABAJO DOCENTE EN LOS INSTITUTOS FEDERALES

\author{
Ecléa Vanessa Canei Baccin* \\ ecleavanessa@gmail.com \\ Eneida Oto Shiroma** \\ eneida.shiroma@ufsc.br
}

\author{
REVISTA PEDAGÓGICA \\ Revista do Programa de Pós-graduação em Educação da Unochapecó | ISSN 1984-1566 \\ Universidade Comunitária da Região de Chapecó | Chapecó-SC, Brasil
}

Como referenciar este artigo: BACCIN, E. V.; SHIROMA, E. O. A intensificação e precarização do trabalho docente nos institutos federais. Revista Pedagógica, Chapecó, v. 18, n. 39, p. 129-15o, set./dez. 2016. DOI: http://dx.doi.org/10.22196/rp.v18i39.3619

RESUMO: Este artigo discute a intensificação do trabalho docente nos Institutos Federais de Educação, Ciência e Tecnologia (IF) diante da reconfiguração da Rede Federal de educação profissional. Utilizando o materialismo histórico como referencial teórico, adota a concepção marxiana de trabalho para problematizar as transformações nos processos de trabalho demandadas pelo capital. Buscamos, com esta análise, levantar aspectos que nos permitam mais bem apreender as contradições da política pública que promove a expansão dos IF simultaneamente à precarização do trabalho que neles se realiza.

Palavras-chave: Trabalho Docente. Intensificação do Trabalho. Precarização. Trabalho e Educação.

ABSTRACT: This article discusses the intensification of teaching work in the Federal Institutes of Education, Science and Technology (IF) facing the reconfiguration of the Brazilian Federal Network of vocational education. Using the historical materialism as a theoretical framework, it adopts the Marxian conception of work to discuss the changes in work processes demanded by capital. This analysis aims at reveal some aspects to understand the contradictions of the public policy that promotes the expansion of IF and simultaneously the precariousness of work that takes place in their interior.

Keywords: Teaching Work. Intensification of Work. Precarization. Work and Education.

RESUMEN: En este artículo se analiza la intensificación del trabajo docente en los Institutos Federales de Educación, Ciencia y Tecnología (IF) frente a la reconfiguración de la Red Federal de la formación professional in Brasil. Utilizando el materialismo histórico como marco teórico, adopta la concepción marxista de trabajo para discutir los cambios en los procesos de trabajo exigidos por el capital. Este análisis tiene como objetivo revelar algunos aspectos para entender las contradicciones de la política pública que promueve la expansión de IF y, simultáneamente, la precariedad del trabajo que se lleva a cabo en su interior.

Palabras clave: Trabajo Docente. Intensificación del Trabajo. La Precariedad. El Trabajo y la Educación. 
* Mestre em Educação pela Universidade Federal de Pelotas (UFPel). Doutoranda do Programa de Pós-graduação em Educação da Universidade Federal de Santa Catarina (UFSC). Pesquisadora do Grupo de Estudos sobre Política Educacional e Trabalho (GEPETO). Bolsista da Coordenação de Aperfeiçoamento de Pessoal de Nível Superior (CAPES).

** Doutora em Educação pela Universidade Estadual de Campinas (UNICAMP). Professora do Programa de Pós-graduação em Educação da Universidade Federal de Santa Catarina (UFSC). Pesquisadora do Grupo de Estudos sobre Política Educacional e Trabalho (GEPETO). Coordenadora da Câmara de Pesquisa do CED. Bolsista Produtividade em Pesquisa do Conselho Nacional de Desenvolvimento Científico e Tecnológico (CNPq).

\section{INTRODUÇÃO}

O objetivo deste artigo é discorrer sobre as transformações no processo de trabalho capitalista em geral e, em particular, sobre a intensificação do trabalho docente nos Institutos Federais de Educação, Ciência e Tecnologia (IF) diante da reconfiguração da Rede Federal. Buscamos, a partir desta análise, levantar aspectos que nos permitam mais bem apreender as contradições da política pública que promove a expansão dos IF simultaneamente à precarização do trabalho que neles se realiza.

As reformas educacionais ocorridas no Brasil nas últimas décadas têm trazido profundas mudanças para os trabalhadores da área educacional no que concerne à formação, ao currículo, às novas formas de ensino e gestão, avaliação, tanto para alunos quanto para os docentes. Essas mudanças foram implantadas na esteira da Reforma do Estado desencadeada em meados dos anos de 1990, durante o governo de Fernando Henrique Cardoso (1995-2002), a qual foi orientada pelos princípios do gerencialismo.

A administração pública gerencial, segundo o Plano Diretor da Reforma do Aparelho do Estado, é

[...] baseada em conceitos atuais de administração e eficiência, voltada para o controle dos resultados e descentralizada para poder chegar ao cidadão, que, numa sociedade democrática, é quem dá legitimidade às instituições e que, portanto, se torna "cliente privilegiado" dos serviços prestados pelo Estado. (BRASIL, 1995, p. 7).

As novas formas de gestão propostas para a educação seguiam as recomendações dos organismos multilaterais e impulsionaram a introdução do gerencialismo na educação. O modelo gerencial caracteriza-se pela descentralização de responsabilidades, ao lado da centralização do controle sobre questões estratégicas como formulações das políticas docentes, currículo e da avaliação. Segundo Lima e Gandin (2012, p. 72), "[...] na perspectiva do Estado gerencialista, o Estado passa a não ser mais o fornecedor de serviços, mas a ter, principalmente, um papel de gerenciador das políticas". Nestes moldes, Bresser-Pereira (1996, p. 1) atribui ao Estado o papel

[...] de facilitar para que a economia nacional se torne internacionalmente competitiva. A regulação e a intervenção continuam necessárias, na educação, na saúde, na cultura, no desenvolvimento tecnológico, nos investimentos em infra-estrutura [sic] - uma intervenção que não apenas compense os desequilíbrios distributivos provocados pelo mercado globalizado, mas principalmente que capacite os agentes econômicos a competir a nível mundial. 
O gerencialismo teve grandes impactos no campo educacional. Segundo Hypólito (2008, p. 77), o modelo gerencialista parece ser hegemônico nas políticas educacionais, "[...] com seus índices de eficiência e produtividade, provas de avaliação em todos os níveis, rankings de escolas, e tantos outros indicadores para orientar o financiamento das políticas de educação ou, melhor, das políticas gerenciais de educação".

Na ótica neoliberal, as políticas educacionais são consideradas "[...] um conjunto de ações, decisões e diretrizes sobre o controle do Estado, que permeiam cada vez mais a economia do país, sendo vistas como um investimento que trará um retorno financeiro" (PUZIOL; SILVA, 2008, p. 2) ou que contribuirá para reduzir custos. As reformas dos anos de 1990 visaram a reduzir e controlar os gastos públicos nas áreas sociais e a maximizar os investimentos, utilizando para isso novas formas de regulação, que atrelam o financiamento à avaliação e atingimento de metas. O imperativo de otimizar recursos pressionou os gestores da educação a recorrerem a terceirizações e parcerias com o setor privado.

Oliveira (2004) afirma que a nova regulação repercute diretamente na composição, estrutura e gestão das redes públicas de ensino alternando a configuração das redes tanto nos seus aspectos físicos e organizacionais na medida em que se adotam conceitos de produtividade, eficácia, excelência e eficiência do setor produtivo para o campo pedagógico. E estes elementos também foram identificados nas pesquisas sobre o trabalho docente realizadas nos Institutos Federais de Ciência e Tecnologia (AZEVEDO, 2011; SHIROMA; LIMA FILHO, 2011; COSTA, 2013; SANTOS, 2013; STERING; PEREIRA, 2013).

Para compreendermos as reformas e políticas educacionais contemporâneas que afetam o trabalho nos IF, procuramos analisá-las a partir de uma perspectiva de totalidade, articulando-as às mudanças ocorridas na produção e às demandas do sistema capitalista contemporâneo de formação para o trabalho simples e complexo (NEVES, PRONKO, 2008). Em seguida, discutiremos sua influência no trabalho e na carreira docente.

\section{PROCESSO DE TRABALHO E SUA INTENSIFICAÇÃO NA SOCIEDADE CAPITALISTA}

Segundo Marx e Engels (1987, p. 27), “[...] o primeiro pressuposto de toda a história humana é naturalmente a existência de indivíduos humanos vivos". Portanto, o primeiro ato histórico é a produção dos meios que permitam satisfazer estas necessidades, "a produção da própria vida material” (MARX; ENGELS, 1987, p. 39). O homem modifica a natureza a fim de transformá-la; consequentemente, esta também o transforma. É uma ação consciente, algo planejado, com objetivo prévio. Para Marx (2014, p. 255), 
1 "Capítulo V, Processo de trabalho e o processo de valorização” (MARX, 2014).
2 "O capital não se importa com a duração de vida da força de trabalho. $\mathrm{O}$ que lhe interessa é única e exclusivamente o máximo de força de trabalho que pode ser posta em movimento numa jornada de trabalho" (MARX, 2014, p. 338).
“[...] o trabalho é, antes de tudo, um processo entre o homem e a natureza, processo este em que o homem, por sua própria ação, medeia, regula e controla seu metabolismo com a natureza". Ou seja, para sobreviver o homem necessita colocar em ação suas forças para modificar a natureza. Em toda formação social, qualquer que seja o modo de produção, o trabalho é condição da existência humana. Porém, a forma com que a sociedade se organiza para concebê-lo, realizá-lo e se apropriar da riqueza produzida diferencia-se em função das relações sociais que são estabelecidas.

$O$ processo de trabalho ${ }^{1}$ se constitui em três momentos: a atividade orientada a um fim, (o trabalho propriamente dito); seu objeto e, seus meios (MARX, 2014). A atividade do homem, no processo de trabalho, com os meios e a transformação do objeto é orientada a um fim, na sociedade capitalista, à produção de mercadorias.

Para o capital,

[...] é evidente que o trabalhador, durante toda sua vida, não é senão força de trabalho, razão pela qual todo o seu tempo disponível é, por natureza e por direito, tempo de trabalho, que pertence, portanto, à autovalorização do capital. Tempo para a formação humana, para o desenvolvimento intelectual, para o cumprimento de funções sociais, para relações sociais, para o livre jogo das forças vitais físicas e intelectuais, mesmo o tempo livre do domingo - e até mesmo no país do sabatismo - é pura futilidade! (MARX, 2014, p. 337).

O Capital com seu ímpeto de se autovalorizar, de produzir mais-valor, explora o trabalhador até a sua exaustão². "O capital é trabalho morto, que, como um vampiro, vive apenas da sucção de trabalho vivo, e vive tanto mais quanto mais trabalho vivo suga" (MARX, 2014, p. 307). O prolongamento da jornada de trabalho de homens e crianças criou uma reação da classe trabalhadora que viu ameaçadas suas condições de existência. Com a luta dos trabalhadores, conquistou-se uma jornada de trabalho legalmente limitada; no entanto, com uma jornada menor, desenvolveu-se outro fenômeno: a intensificação do trabalho. Então, a partir do momento em que

[...] a produção crescente de mais-valor mediante o prolongamento da jornada de trabalho estava de uma vez por todas excluída, o capital lançou-se com todo seu poder e plena consciência à produção de mais-valor relativo por meio do desenvolvimento acelerado do sistema da maquinaria. Ao mesmo tempo, operou-se uma modificação no caráter do mais-valor relativo. Em geral, o método de produção do mais-valor relativo consiste em fazer com que o trabalhador, por meio do aumento da força produtiva do trabalho, seja 
capaz de produzir mais com o mesmo dispêndio de trabalho no mesmo tempo. (MARX, 2014, p. 482).

O sistema capitalista passou por várias transformações a fim de superar crises, recessões e de se reinventar para lidar com as contradições que lhe são intrínsecas. Diante da necessidade crescente de extração de mais-valor, o capital desenvolveu estratégias para aumentar a produtividade diante do limite da extensão da jornada de trabalho. O investimento no avanço das forças produtivas veio acompanhado de medidas como queima de capital, demissões em massa, férias coletivas, redução salarial, flexibilização do contrato trabalhista, dentre tantas outras táticas para administrar essas crises cujos efeitos são sentidos, mormente, pela classe trabalhadora.

O Fordismo considerado paradigma da produção em massa do século XX teve seu auge do pós-guerra aos anos de 1970, a partir da exploração de enorme contingente de operários contratados para realizar trabalhos simples e repetitivos (ANTUNES, 2000; PINTO, 2010).

O trabalho simples e o trabalho complexo referem-se à divisão social do trabalho presente em qualquer sociedade, mas são historicamente determinados, ou seja, sofrem influências do modo de produção ao qual estão submetidos. O trabalho simples corresponde ao dispêndio da força de trabalho sem qualquer desenvolvimento especial, que toda pessoa possui em seu organismo corpóreo e "o trabalho mais complexo vale apenas como trabalho simples potenciado ou, antes, multiplicado" (MARX, 2014, p. 122). Ou seja, o trabalho complexo caracteriza-se por sua natureza especializada, necessita, em razão disso, de um maior tempo de formação que o trabalho simples.

Na década de 1970, diante da superprodução de capital e do agitado contexto político de movimentos operários, estudantis, e de resistência aos regimes ditatoriais, o capital empreendeu significativas mudanças na organização e gestão do trabalho e da produção inspirado no modelo desenvolvido por Taiichi Ohno, na fábrica da Toyota, no pós-segunda Guerra Mundial. Esse modelo de organização do trabalho que utiliza máquinas flexíveis possibilita o planejamento de uma produção de escopo, puxada pela demanda, evitando a formação de estoques. Além dos aspectos de melhoria na transparência e no monitoramento da produção possibilitados pelo sistema Just In Time, da tecnologia programável que possibilita a produção customizada, a reestruturação produtiva provocou impactos sociais importantes (SHIROMA, 1993). Assim, comparado à rigidez da organização do trabalho taylorista-fordista,

[...] o toyotismo pode parecer um modelo de produção e gerenciamento da força de trabalho melhor, e de fato o é. Mas não para os trabalhadores, e sim para o capital, pois além das técnicas já experimentadas e 
desenvolvidas pelos modelos de Ford e Taylor, o Sistema Toyota de Produção aprimorou a intensificação do trabalho e ampliou as dimensões da exploração da força de trabalho quando sistematizou as técnicas de apropriação da subjetividade. (BATISTA, 2008, p. 11).

Alves e Moraes (2006) referem-se a esse processo como expropriação da subjetividade do trabalhador. Diferente do fordismo, o toyotismo demanda trabalhadores multifuncionais, mais qualificados para "vestirem a camisa da empresa”, desempenharem várias funções, dotados de atributos como flexibilidade, criatividade, iniciativa, capacidade para trabalhar em equipe, gerir imprevistos e inovar.

Todo esse processo de transformações no chão de fábrica, na gestão da produção, na administração dos trabalhadores, nas relações interfirmas, o qual é referido na literatura como Reestruturação Produtiva, desencadeou um conjunto de políticas, de ações estatais que tiveram

[...] como base ajustes estruturais nas contas nacionais, afetando desde as políticas sociais até a continuidade do investimento estatal direto nos setores produtivos e financeiros, submetendo a alocação dos recursos e dos resultados econômicos ao movimento de livre mercado. (PINTO, 2010, p. 48).

Dessa forma, o capital passou a demandar, de parte minoritária dos trabalhadores, maior escolaridade, múltiplas capacidades, uma carteira de competências e habilidades que indicassem seu potencial. Em outras palavras, as transformações no desenvolvimento do capitalismo e a mundialização do capital acarretaram mudanças na formação do trabalhador. Contraditoriamente, o aumento de exigências de qualificação vem acompanhado de formas cada vez mais precarizadas de trabalho, com contratos temporários, terceirizações, entre outras que representam perdas dos direitos conquistados. E este não foi um fenômeno que atingiu apenas a esfera do setor produtivo. Atingiu outros setores, inclusive o sistema educacional, o que acabou acirrando a intensificação do trabalho.

A seguir, buscamos trazer elementos para a discussão da intensificação do trabalho na sociedade capitalista e analisar esse processo mais especificamente no trabalho docente.

\subsection{Intensificação do trabalho docente na sociedade capitalista}

Chama-se intensificação do trabalho aos processos que resultam em maior dispêndio das capacidades físicas, cognitivas e emotivas do trabalhador com o objetivo de elevar quantitativamente ou melhorar qualitativamente os 
resultados. Em síntese, mais trabalho. (DAL ROSSO, 2006, p. 70).

As empresas investem cada vez mais em técnicas que visam à identificação dos funcionários, com o objetivo e as metas nas mesmas, transformando os trabalhadores em "colaboradores" e, dentro desse viés, estes acabam imprimindo mais esforços para cumprir prazos e entregas para os clientes. A depender do tipo de emprego, as tecnologias aliadas aos meios de comunicação ajudam no monitoramento e na pressão pelos cumprimentos dos prazos e das metas, uma vez que os trabalhadores, embora não estejam em seus locais de trabalho e em período de labor, respondem $e$-mails e mensagens com conteúdo ligado ao seu emprego. Essa intensificação ocorre para o conjunto da classe trabalhadora e traz graves consequências para a saúde do trabalhador.

O trabalho docente, como parte do trabalho em geral, também vem sofrendo com a intensificação e a precarização em diversos aspectos, assim como com a perda de direitos historicamente conquistados, a fragmentação da carreira, e suas próprias condições de ensino, pois, muitas vezes, os educadores não possuem locais de trabalho adequados, nem materiais disponíveis para o bom desenvolvimento de suas aulas. Cabe destacar que o trabalho docente envolve,

[...] por sua vez, elementos típicos do desgaste físico, como também os decorrentes da pressão por mais resultados. Um bom número das consequências das condições do trabalho sobre os professores não apresenta um quadro diferente dos tradicionais problemas sentidos pelos trabalhadores do ramo. Entre estes, podemos citar os problemas de alergia a giz, os problemas de garganta, rouquidão e nódulos nas cordas vocais. Outro conjunto de sintomas declarados, no entanto, revela o efeito do trabalho intelectual prolongado, típico do perfil das doenças decorrentes do trabalho submetido a forte pressão por resultados, com atribuições de responsabilidades, com altos graus de flexibilidade e versatilidade. Entre eles, estão o estresse, as gastrites crônicas e as lesões por esforços repetitivos. (DAL ROSSO, 2006, p. 86).

Concordamos com a seguinte afirmação de Santos (2013, p. 53): "[...] o trabalho docente, mesmo que de forma parcial, sem se constituir num trabalho que gera mais-valor, está condicionado à lógica do capital e também sofre um processo de intensificação". As escolas ou as universidades públicas não são produtoras diretas de mais-valor; porém, desempenham papéis fundamentais para o bom funcionamento da sociedade capitalista, não somente através da produção de consciência e hegemonia mas também da produção e reprodução da lógica capitalista, visto que desempenham um papel na produtividade ao criar, gerar tecnologias, inovações, patentes, consultorias, pesquisa aplicada etc. 
Consideramos que é fundamental que se compreendam as relações capitalistas como relações sociais, ou seja, como relações de classe. A função desempenhada pela escola vai além do plano ideológico, "[...] o trabalho especificamente improdutivo - aquele que não produz mais-valor -, porque, posto pela própria organicidade do capital, se constitui em algo necessário à sustentação e continuidade do modo capitalista de produção" (FRIGOTTO, 1989, p. 154). Logo, imediatamente a escola de gestão exclusivamente pública não produz mais-valor; mas, indiretamente, está formando o sujeito que irá produzi-la com seu trabalho, evidenciando o papel da educação como parte das condições sociais de produção necessárias à reprodução do modo de produção capitalista.

As ciências humanas estão envolvidas no aumento da produtividade para diminuição do valor das mercadorias, qualificando a força de trabalho. Para isso, é necessária uma educação cada vez mais variada de acordo com a demanda do desenvolvimento das forças produtivas, pois estas exigem a qualificação dos trabalhadores, onde o que está em curso é um "[...] novo modo de fazer científico, principalmente no que diz respeito à aplicação imediata do conhecimento para atender aos interesses da sociedade mercantil" (COSTA, 2013, p. 15). Contraditoriamente, a educação não atende apenas aos interesses do capital. A classe trabalhadora luta historicamente pelo acesso à educação e à cultura como forma de potencializar a compreensão crítica da realidade, a organização para a luta e a emancipação.

As demandas de capital e trabalho confluíram para a criação e a reestruturação de instituições educacionais; todavia, desacompanhadas das condições adequadas de trabalho, considerando a infraestrutura, pessoal, entre outros. Por essa razão, destacamos a relevância de se compreender o processo de intensificação do trabalho docente associado à expansão do no bojo do contexto atual de desenvolvimento das forças produtivas, das mudanças no mundo do trabalho. Nas universidades, observa-se um crescimento da pesquisa e consultorias para o setor privado, precarização do trabalho docente, com políticas públicas que visam a aumentar os números de matrícula; porém, sem a infraestrutura adequada, muito menos com o número necessário de professores e de técnicos administrativos. Segundo Colares e Sindeaux (2015, p. 67), essa mesma lógica de expansão, sem ter as condições necessárias para a sua realização "[...] acabou por orientar a criação e expansão dos Institutos Federais de Educação, Ciência e Tecnologia, tendo apresentado as mesmas implicações de precarização para os cargos de EBTT", como veremos a seguir.

\subsection{Intensificação do trabalho dos professores dos institutos federais de ciência e tecnologia}

A carreira do Ensino Básico, Técnico e Tecnológico (EBTT) foi criada em 2008, com a Lei no 11.784 (BRASIL, 2008a), pois até então vigia a carreira do Magistério de 
$1^{0}$ e $2^{0}$ Graus. Essa nova configuração foi necessária para acompanhar a ampliação das funções docentes que ocorria nos IF. Os docentes passaram a atuar em diferentes níveis e modalidades de ensino, desde o ensino médio, técnico, graduação e pós-graduação, além do ensino, da pesquisa e extensão.

A Lei ${ }^{0} 11.892$, de 29 de dezembro de 2008, instituiu a Rede Federal de Educação Profissional Científica e Tecnológica e criou os Institutos Federais de Educação, Ciência e Tecnologia (BRASIL, 2008b). Mas a história da Rede Federal de Educação Profissional, Científica e Tecnológica começou em 1909, quando o então Presidente da República, Nilo Peçanha, criou 19 escolas de Aprendizes e Artífices que, mais tarde, deram origem aos Centros Federais de Educação Profissional e Tecnológica (CEFETs.) (OTRANTO, 2011). A Educação Profissional no Brasil surgiu com o objetivo de ensinar ofícios às pessoas consideradas pobres e ocupar os "desvalidos", as pessoas que eram consideradas desocupadas, como estratégia de redução da criminalidade e da pobreza (COSTA, 2013; TAVARES, 2015).

As Escolas Técnicas Industriais foram transformadas em autarquias em 1959, passando a ser denominadas de Escolas Técnicas Federais. A partir desse momento, as escolas ganharam autonomia didática e de gestão. Em 1978, três Escolas Técnicas Federais, dos estados do Paraná, Minas Gerais e Rio de Janeiro, deram início ao processo de transformação que originou os CEFETs.

No ano de 1994, foi criado o Sistema Nacional de Educação Tecnológica, transformando outras Escolas Técnicas Federais, além das Escolas Agrotécnicas Federais em Centros Federais de Educação Tecnológica. Esse processo de transformação ocorreu de forma gradativa e obedeceu a critérios estabelecidos pelo Ministério de Educação. Em 1997, com a assinatura do Decreto $\mathrm{n}^{0} 2.208$, a educação profissional foi regulamentada. O processo de transformação das Escolas Técnicas Federais em Centro Federal de Educação Tecnológica foi retomado em 1999.

O projeto de Educação Tecnológica iniciou ainda no mandato do presidente Fernando Henrique Cardoso e teve continuidade nos dois mandatos do Governo Lula (20032010) e nos de Dilma (2011-2016), tendo como referencial normativo a Lei ${ }^{0}$ 9.394, de 20 de dezembro de 1996 - Lei de Diretrizes e Bases da Educação (BRASIL, 1996). Transformou as escolas técnicas em CEFETs e transformou o CEFET-Paraná em Universidade Tecnológica. Foi a partir da Lei $\mathrm{n}^{0}$ 11.892/2008, que aos CEFETs e às demais escolas profissionalizantes foi aberta a possibilidade de se transformarem em Institutos Federais de Educação, Ciência e Tecnologia.

A Rede Federal de Educação Profissional e Tecnológica passou por uma expansão e foi reconfigurada a partir da criação dos 38 Institutos Federais de Educação, Ciência e Tecnologia com a Lei ${ }^{0}{ }_{11.892 / 2008}$. Os Institutos Federais são instituições de educação superior, básica e 
profissional, especializados na oferta de educação profissional e tecnológica nas diferentes modalidades de ensino.

$\S 1^{\circ}$ Para efeito da incidência das disposições que regem a regulação, avaliação e supervisão das instituições e dos cursos de educação superior, os Institutos Federais são equiparados às universidades federais.

$\S 2^{\mathrm{a}}$ No âmbito de sua atuação, os Institutos Federais exercerão o papel de instituições acreditadoras e certificadoras de competências profissionais. (BRASIL, 2008b).

De acordo com dados do Ministério da Educação até o ano de 2002, a Rede Federal de Educação Profissional, Científica e Tecnológica era composta por 140 escolas técnicas no país. Entre 2003 e 2010, o número de instituições federais de educação profissional saltou de 140 para 354 . Entre 2011 a 2014, foram 208 novas unidades que entraram em funcionamento, totalizando 562 escolas em atividade. Dessa forma, a Rede Federal é constituída por 38 Institutos Federais, bem como por instituições que não aderiram aos Institutos Federais, sendo dois CEFETs, 25 escolas vinculadas a universidades e uma universidade tecnológica.

Com as transformações no processo produtivo, foi se modificando o nível de qualificação exigida dos trabalhadores para que percebessem o desenvolvimento de novas tecnologias. As transformações no mundo do trabalho necessitam de um trabalho complexo para atender às demandas do capital; portanto, faz-se necessário adequar também as instituições formadoras dessa força de trabalho.

Essas mudanças tendem, de um lado, à homogeneização do patamar mínimo de escolarização para o "trabalho complexo" no nível superior de ensino e, de outro lado, ao surgimento de cursos de mais curta duração (cursos seqüenciais [sic] para a formação científica e cursos de tecnólogos para a formação tecnológica). (LIMA; NEVES; PRONKO, 2008, p. 418).

É preciso compreender e buscar as relações da "[...] produção combinada de trabalho simples e complexo e o papel do sistema escolar na sua dupla tarefa de formação-técnica e conformação ético-política para o trabalho/ vida em sociedade" (NEVES; PRONKO, 2008, p. 10). Essa síntese oferece elementos importantes para compreensão da política de expansão dos IF nos últimos 15 anos. Mas precisamos nos questionar, ainda que o acesso à educação seja uma reivindicação histórica dos trabalhadores, que interesses estão por trás desta expansão, bem como, de que forma a ela vem sendo feita?

Estudos de Souza (2013) indicam que a reforma e a expansão do ensino técnico têm relações substanciais com o projeto "neodesenvolvimentista" do governo do Partido dos Trabalhadores. 
3 No relatório, PTF é sinônimo de inovação.

A partir do segundo mandato do governo Lula da Silva (2007-2010), esse projeto foi impulsionado pelo Programa de Aceleração do Crescimento (PAC), lançado em janeiro de 2007. No bojo do PAC, estava o Plano de Desenvolvimento da Educação (PDE), que anunciou a maior expansão já ocorrida na Rede Federal de Educação Profissional e Tecnológica. (SOUZA, 2013, p. 8).

O documento de Concepção e diretrizes lançado pelo Ministério da Educação (MEC) expõe que "o foco dos Institutos Federais será a justiça social, a equidade, a competitividade econômica e a geração de novas tecnologias" (BRASIL, 2010, p. 3). Essa inflexão dos IF para assumirem objetivos de inclusão social remonta ao período histórico em que a preocupação da Educação Profissional era com os "desvalidos". De alguma forma, os IF estão sendo induzidos a retomar este objetivo:

[...] o Banco Mundial (1994) tem indicado o papel do Ensino Superior para o "alívio da pobreza", enfatizando que esse nível de ensino tem a responsabilidade de formar pessoas que devem desempenhar cargos de responsabilidade nos setores públicos e privados, forjando a identidade nacional, contribuindo para o aumento da produtividade do trabalho, e para o crescimento econômico. (MAUÉS; SEGENREICH; OTRANTO, 2015, p. 44).

Segundo o Banco Mundial (2008), o Brasil precisa ampliar as reformas e aumentar a eficiência da Produtividade Total dos Fatores (PTF) ${ }^{3}$, pois com o aumento da produtividade, crescem os incentivos para as empresas inovarem e investirem na melhoria da capacidade dos profissionais.

O Banco Mundial (2008, p. 41) afirma que, “[...] o que se quer tornar claro é que o Brasil precisa implementar um processo de reforma amplo e sistêmico para aumentar a competitividade de sua economia e acelerar o seu crescimento".

As transformações da produtividade estão relacionadas às melhorias no nível educacional, da capacitação e da tecnologia e "o sistema educacional do País, e não os empregadores, deveria se responsabilizar pela formação básica” (BANCO MUNDIAL, 2008, p. 212). Portanto, segundo o Banco Mundial, é necessário modificar o sistema educacional a fim de atender às demandas do mercado de trabalho.

As modificações necessárias para o mercado de trabalho exigem trabalhadores mais flexíveis, que produzam mais e melhor, que sejam capazes de desempenhar diferentes tarefas. Na carreira docente, tais modificações afetam circunstancialmente a atividade deste profissional, 
com uma demanda que muitas vezes vai além do tempo estipulado em seu contrato de trabalho, exigindo um compromisso com uma demanda cada vez maior. Pinto et al. (2013, p. 50), em pesquisa realizada em um Instituto Federal de Educação, Ciência e Tecnologia, apresenta uma série de atividades relatadas pelos professores que acaba por intensificar o trabalho dos mesmos:

[...] grande número de horas-aula, orientação dos alunos da pós-graduação fora da carga horária, estudo, pesquisa, leituras, planejamento de aulas bastante diferenciadas, correção de instrumentos avaliativos, exigências burocráticas (preenchimento diário do sistema de registros de faltas e notas), participação em conselhos de classe, reuniões nos diferentes espaços de atuação, escrita de artigos para publicação em eventos e participação nos mesmos, escrita de artigos para revistas e livros, atuação em bancas de defesa de trabalhos acadêmicos, encaminhamento de projetos para órgãos de financiamento etc. Algumas tarefas de cunho burocrático impostas pela instituição foram mencionadas, tais como: o excesso de atividades-deveres, causando a morte do desejo, a burocracia institucional, a política institucional que prioriza a quantidade em detrimento da qualidade.

Além do que foi apresentado, ainda temos a questão da falta de docentes, o que acaba sobrecarregando o trabalho dos que estão na ativa. O Tribunal de Contas da União (TCU) realizou uma auditoria Operacional e Fiscalização de orientação centralizada da Rede Federal de Educação Profissional, desenvolvida no período de agosto de 2011 a abril de 2012. A auditoria privilegiou temas relacionados com a cadeia de resultados da Educação Profissional, avaliando a atuação dos Institutos Federais com relação aos seguintes temas: a) caracterização da evasão e medidas para reduzi-la; b) interação com os arranjos produtivos locais; c) integração acadêmica entre as áreas de pesquisa e extensão; d) iniciativas de apoio à inserção profissional dos alunos no mercado de trabalho; e) infraestrutura e suporte à prestação dos serviços educacionais (BRASIL, 2012). Dentre outros aspectos, apresentou dados que revelam a carência de 7.966 professores, o que representa 19,7\% do total de cargos.

Como consequências da carência de docentes, estão: a) sobrecarga dos professores, que são chamados a ministrar disciplinas em áreas diversas daquela para a qual foram contratados; b) postergação da oferta de uma disciplina até que se consiga um professor qualificado para a tarefa; c) turmas grandes a ponto de pôr em risco a aprendizagem dos alunos, fato frequente segundo $26 \%$ dos docentes ouvidos. (BRASIL, 2012, p. 47). 
Após essa análise, não foi realizada outra pelo TCU. Em relação a esses dados acerca da falta de professores, não foram encontradas pesquisas abrangentes para averiguar se esse número diminuiu, mas as estatísticas realizadas pela Secretaria de Educação Profissional e Tecnológica (SETEC) foram disponibilizadas no Relatório anual de análise dos indicadores de gestão das Instituições Federais de Educação Profissional, Científica e Tecnológica conforme indicam as Tabelas.

Tabela 1 - Relação de alunos por docente em tempo integral (dados de 2012)

\begin{tabular}{|c|c|c|c|}
\hline \multicolumn{4}{|c|}{ RAD - Dados de 2012} \\
\hline Região & Matriculados & Docentes & 2012 \\
\hline Norte & 81494 & 2520,5 & 32,33 \\
\hline Nordeste & 238663 & 8764 & 27,23 \\
\hline Centro-Oeste & 63352 & 2560 & 24,75 \\
\hline Sudeste & 218578 & 7403 & 29,53 \\
\hline Sul & 136117 & 3824,5 & 35,59 \\
\hline Total & $738.204,00$ & $25.072,00$ & 29,44 \\
\hline
\end{tabular}

Fonte: Brasil (2015).

Tabela 2 - Relação de alunos por docente em tempo integral (dados de 2013)

\begin{tabular}{|r|r|r|r|}
\hline \multicolumn{5}{|c|}{ RAD - Dados de 2013 } \\
\hline \multicolumn{1}{|c|}{ Região } & Matriculados & Docentes & \multicolumn{1}{c|}{$\mathbf{2 0 1 3}$} \\
\hline Norte & 85.186 & 2.875 & 29,6 \\
\hline Nordeste & 260.451 & 9.551 & 27,3 \\
\hline Centro-Oeste & 83.094 & 2.756 & 30,2 \\
\hline Sudeste & 243.724 & 7.831 & 31,1 \\
\hline Sul & 131.588 & 4.226 & 31,1 \\
\hline Total & $\mathbf{8 0 4 . 0 4 3}$ & $\mathbf{2 7 . 2 3 9}$ & $\mathbf{2 9 , 5}$ \\
\hline
\end{tabular}

Fonte: Brasil (2015).

Tabela 3 - Relação de alunos por docente em tempo integral (dados de 2014)

\begin{tabular}{|c|c|c|c|}
\multicolumn{5}{|c|}{ RAD - Dados de 2014} \\
\hline Regiåo & Matriculados & Docentes & 2014 \\
\hline Norte & 74.678 & $2.933,5$ & 25,46 \\
\hline Nordeste & 248.555 & $9.885,0$ & 25,14 \\
\hline Centro-Oeste & 57.266 & $2.956,0$ & 19,37 \\
\hline Sudeste & 195.665 & $9.066,1$ & 21,58 \\
\hline Sul & 102.272 & $4.654,5$ & 21,97 \\
\hline Total & $\mathbf{6 7 8 . 4 3 6}$ & $\mathbf{2 9 . 4 9 5}$ & $\mathbf{2 3 , 0 0}$ \\
\hline
\end{tabular}

Fonte: Brasil (2015).

Segundo o relatório anual de análise dos indicadores de gestão das instituições Federais de Educação Profissional Científica e Tecnológica, o número de docentes no ano de 2011 foi de 25.022; em 2012, não houve aumento significativo ficando um total de 25.072; em 2013, foram 27.239; e em 2014, 29.495 professores. 
O relatório do TCU, citado anteriormente, referente a 2012, apresenta um universo de pouco mais de 22 mil professores na Rede Federal. Constatamos, assim, divergências dos dados apresentados em relação ao número total de professores da Rede Federal. Outro ponto importante a ser destacado é que não se publicam dados sobre o número de professores efetivos na carreira e o número de substitutos. Estes últimos não têm os direitos trabalhistas dos primeiros. Eles são contratados com um salário menor, por no máximo dois anos, e somente para dar aula, sendo excluídos dos projetos de pesquisa e extensão.

Em relação às matrículas, o relatório aponta que em 2012, foram registradas 738.204 matrículas na Rede Federal; em 2013, foram registradas 804.043 matrículas na Rede Federal; e, em 2014, foram registradas 678.436 matrículas. O número de matrículas é o número de referência para dimensionar os índices de concluintes e de retidos.

O total de concluintes, em escala nacional, foi de 77.106 [em 2014], o que resultou em um índice de $11,37 \%$ de concluintes por matrícula. Em 2010, esse índice foi de 12,8\%, apresentando um pequeno aumento em 2011 e 2012, que foram $15,4 \%$ e $15,2 \%$, respectivamente. Em 2013, ocorreu um decréscimo para $12,97 \%$, atribuído à greve ocorrida na Rede Federal. Os efeitos da greve, por inércia, podem estar influindo no indicador em 2014, que se reduziu para $11,37 \%$. Além disso, a forte expansão da Rede, com a entrada de novos campi e novos cursos em funcionamento, provocam aumento nas matrículas que terão concluintes apenas ao término do ciclo de matrícula, cujos períodos variam de três a quatro anos, dependendo do tipo de curso. (BRASIL, 2015, p. 24).

Em relação aos índices de concluintes, a secretaria destacou o decréscimo dos anos de 2013 e 2014 e atribuiu a culpa aos docentes em função da greve ocorrida na rede Federal.

Considerando que ainda em 2012 havia falta de quase 8 mil professores, que a expansão da Rede Federal entre 2011-2014 foi ampliada em 208 novas unidades e que as matrículas aumentaram dois anos consecutivos, a grande probabilidade do déficit de professores ter se elevado.

\section{ALGUMAS CONSIDERAÇÕES ACERCA DA DISCUSSÃO}

O governo afirma incentivar e ampliar/expandir o ensino; porém, ao mesmo tempo em que vemos o número de matrículas aumentar, são anunciados cortes de verbas públicas para a educação, agravando o quadro de uma infraestrutura precária que não consegue atender à nova demanda de ingressos nos cursos, e professores 
${ }^{4}$ Servidores do IFPI devem registrar frequência com ponto eletrônico. Disponível em: <http://www5.ifpi.edu.br/index. php?option $=$ com_content\&view $=$ article \&id=2720 $>$; Sistema eletrônico de ponto começa nesta terça, $1^{\circ}$, no Câmpus Rio Grande. Disponível em: <http://www. riogrande.ifrs.edu.br/site/conteudo. php?cat $=5 \&$ sub $=1674>$.

${ }^{5}$ ANDES-SN alerta para implantação ilegal de ponto eletrônico em IF. [s. d.]. Disponível em: <http://www.andes.org.br/andes/ print $>$.

${ }_{6}$ TRF4 mantém ponto eletrônico para professores do IFRS de Rio Grande (RS). Disponível em: <http://www2.trf4.jus. $\mathrm{br} / \mathrm{trf} 4 /$ controlador.php?acao $=$ noticia visualizar\&id_noticia $=10446>$.

\footnotetext{
7 Referente à greve do Sindicato Nacional dos Docentes das Instituições De Ensino Superior (ANDES/SN). A greve do Sindicato Nacional dos Servidores Federais da Educação Básica, Profissional e Tecnológica (SINASEFE) durou 125 dias em 2015.
}

sobrecarregados, estressados, adoecem devido à carga crescente de atividades. Como apontamos no decorrer do artigo, são várias as formas de precarização do trabalho docente, além dos contratos temporários, das terceirizações, há muitas alterações e condicionalidades para as atividades de pesquisa, que afetam também as atividades de ensino e extensão. Com a falta de laboratórios, bibliotecas e salas de aula (BRASIL, 2012), esse processo se consolida com a lógica gerencial voltada para a educação, acarretando intensificação do trabalho docente. Cada vez mais, criam-se formas de regular e controlar o trabalho dos professores, e de responsabilizá-los pelo sucesso ou fracasso da educação.

A pressão exercida para aumentar a quantidade de trabalho dentro da jornada geralmente de 40 horas se concretiza também alicerçada na ideia de que os docentes deveriam ser "mais produtivos", correspondendo à "produção" a qualidade de "produtos" relacionados ao mercado (aulas, orientações, publicações, projetos, patentes etc.) expelidos pelo docente. (BOSI, 2011, p. 66).

Nesse processo desenfreado de exigência de produtividade, pouco ou nada se importa com a saúde dos trabalhadores, seja ela física (dores musculares, problemas posturais, lesões por esforços repetitivos etc.) ou psicológica devido à grande pressão sofrida pelos docentes. Outra forma de pressão é o controle da jornada de trabalho diária dos servidores de IF através de ponto eletrônico4. O Sindicato Nacional dos Docentes das Instituições de Ensino Superior (ANDES/SN) divulgou nota ${ }^{5}$ alertando sobre a ilegalidade do ponto eletrônico e pediu a resistência ${ }^{6}$ dos professores a essa medida.

A criação e expansão dos Institutos Federais de Ciência e Tecnologia, afirma a Educação Profissional e Tecnológica como uma política pública, segundo o Documento de Concepção e Diretrizes (2010). Em seu discurso, "[...] pauta-se no compromisso de assegurar aos profissionais formados a capacidade de manter-se permanentemente em desenvolvimento" (BRASIL, 2010, p. 6). Todavia, os investimentos para a formação e qualificação da força de trabalho, no contexto apresentado das relações de produção capitalista, acontecem para adaptar ainda mais os trabalhadores a esta ordem e não para melhorar as suas vidas.

Os processos de precarização e intensificação do trabalho acabam, em muitos casos, sendo naturalizados pelos docentes. Por outro lado, muitos professores não ficam imóveis diante de tal situação; portanto, lutam para não apenas suas melhorar as condições de trabalho ou salariais mas também estão preocupados como a melhoria da educação pública. Podemos citar como resistência as duas últimas greves da categoria. A greve de 2012 que durou 125 dias e a recente greve de 2015 com duração de 139 dias $^{7}$. A resposta a essas políticas e reformas precisa ser de intensa 
luta frente aos ataques que a classe trabalhadora vem sofrendo.

\section{REFERÊNCIAS}

ALVES, Giovanni; MORAES, Lívia. Trabalho e estratégias empresariais no capitalismo global toyotismo e "captura" da subjetividade. Mediações - Revista de Ciências Sociais, Londrina, v. 11, n. 1, p. 105-124, 2006.

ANTUNES, Ricardo. Fordismo, toyotismo e acumulação flexível. In: ANTUNES, Ricardo. Adeus ao trabalho? Ensaio sobre as metamorfoses e a centralidade do mundo do trabalho. 5. ed. São Paulo: Cortez; Campinas: Ed. da Universidade Estadual de Campinas, 2000. p. 21-46.

AZEVEDO, Luiz Alberto de. De CEFET a IFET. Cursos superiores de tecnologia no Centro Federal de Educação Tecnológica de Santa Catarina: gênese de uma nova institucionalidade? 2011. 383 f. Tese (Doutorado em Educação) - Programa de Pós-Graduação em Educação, Universidade Federal de Santa Catarina, 2011.

BANCO MUNDIAL. Conhecimento e inovação para a competitividade. Tradução: Confederação Nacional da Indústria (CNI). Brasília, 2008. Disponível em: <http:// arquivos.portaldaindustria.com.br/app/conteudo_18/2 012/08/16/1409/20120822122349778395i.pdf>. Acesso em: 26 fev. 2015 .

BATISTA, Erika. Fordismo, taylorismo e toyotismo: apontamentos sobre suas rupturas e continuidades. In: SIMPÓSIO LUTAS SOCIAIS NA AMÉRICA LATINA, 3., 24-26 set. 2008, Londrina. Anais... Londrina: UEL, 2008. p. 1-12. Disponível em: <http://www.uel.br/grupopesquisa/gepal/terceirosimposio/erika_batista.pdf $>$. Acesso em: 7 jan. 2016

BOSI, Antônio de Pádua. Precarização do trabalho docente no Brasil: Novas e velhas formas da dominação capitalista (1980-2005) In: BOSI, Antônio de Pádua. Precarização e intensificação do trabalho no Brasil recente. Ensaio sobre o mundo dos trabalhadores. 1. ed. Cascavel: Edunioste, 2011. p. 51-77.

BRASIL. Câmara da reforma do Estado. Plano Diretor da Reforma do Aparelho do Estado. Brasília, 1995. Disponível em: <http://www.bresserpereira.org.br/ Documents/MARE/PlanoDiretor/planodiretor.pdf $>$. Acesso: 15 jan. 2016.

BRASIL. Decreto n. 2.208, de 17 abril de 1997. Regulamenta o parágrafo $2^{\circ}$ do art. 36 e os artigos 39 a 42 da Lei n. 9.394, de 20 de dezembro de 1996, que estabelece as diretrizes 
e bases da educação 62 Educação \& Sociedade, ano XXI, $\mathrm{n}^{0}$ 70, Abril/oo nacional. In: SINDOCEFET-PR/ANDESSN. A verdade sobre a reforma da educação profissional. Curitiba: Gráfica e Editora Popular.

BRASIL. Lei $\mathrm{n}^{0}$ 9.394, de 20 de dezembro de 1996. Estabelece as diretrizes e bases da educação nacional. Diário Oficial da República Federativa do Brasil, Brasília, DF, 23 dez. 1996. Disponível em: <http://www. planalto.gov.br/ccivil_03/_Ato2011-2014/2014/Lei/ L13005.htm>. Acesso em: 13 jan. 2014.

BRASIL. Lei n. 11.784, de 22 de setembro de 2008a. Dispõe sobre a reestruturação do Plano Geral de Cargos do Poder Executivo - PGPE, de que trata a Lei no 11.357, de 19 de outubro de 2006, do Plano Especial de Cargos da Cultura, de que trata a Lei no 11.233, de 22 de dezembro de 2005, do Plano de Carreira dos Cargos Técnico-Administrativos em Educação, de que trata a Lei no 11.091, de 12 de janeiro de 2005, da Carreira de Magistério Superior, de que trata a Lei no 7.596, de 10 de abril de 1987, do Plano Especial de Cargos do Departamento de Polícia Federal, de que trata a Lei no 10.682, de 28 de maio de 2003, do Plano de Carreira dos Cargos de Reforma e Desenvolvimento Agrário, de que trata a Lei no 11.090, de 7 de janeiro de 2005, da Carreira de Perito Federal Agrário, de que trata a Lei no 10.550, de 13 de novembro de 2002, da Carreira da Previdência, da Saúde e do Trabalho, de que trata a Lei no 11.355, de 19 de outubro de 2006, da Carreira de Fiscal Federal Agropecuário, de que trata a Medida Provisória no 2.22943, de 6 de setembro de 2001, e a Lei no 10.883, de 16 de junho de 2004, dos Cargos de Agente de Inspeção Sanitária e Industrial de Produtos de Origem Animal, Agente de Atividades Agropecuárias, Técnico de Laboratório e Auxiliar de Laboratório do Quadro de Pessoal do Ministério da Agricultura, Pecuária e Abastecimento, de que tratam respectivamente as Leis nos 11.090 , de 7 de janeiro de 2005, e 11.344, de 8 de setembro de 2006, dos Empregos Públicos de Agentes de Combate às Endemias, de que trata a Lei no 11.350 , de 5 de outubro de 2006, da Carreira de Policial Rodoviário Federal, de que trata a Lei no 9.654, de 2 de junho de 1998, do Plano Especial de Cargos do Departamento de Polícia Rodoviária Federal, de que trata a Lei no 11.095, de 13 de janeiro de 2005, da Gratificação de Desempenho de Atividade de Execução e Apoio Técnico à Auditoria no Departamento Nacional de Auditoria do Sistema Único de Saúde - GDASUS, do Plano de Carreiras e Cargos do Hospital das Forças Armadas - PCCHFA, do Plano de Carreira e Cargos de Magistério do Ensino Básico, Técnico e Tecnológico, e do Plano de Carreira do Ensino Básico Federal; fixa o escalonamento vertical e os valores dos soldos dos militares das Forças Armadas; altera a Lei no 8.745, de 9 de dezembro de 1993, que dispõe sobre a contratação por tempo determinado para atender à 
necessidade temporária de excepcional interesse público, a Lei no 8.112, de 11 de dezembro de 1990, que dispõe sobre o regime jurídico dos servidores públicos civis da União, das autarquias e das fundações públicas federais, a Lei no 10.484, de 3 de julho de 2002, que dispõe sobre a criação da Gratificação de Desempenho de Atividade Técnica de Fiscalização Agropecuária - GDATFA, a Lei no 11.356, de 19 de outubro de 2006, a Lei no 11.507, de 20 de julho de 2007; institui sistemática para avaliação de 24 desempenho dos servidores da administração pública federal direta, autárquica e fundacional; revoga dispositivos da Lei no 8.445, de 20 de julho de 1992, a Lei no 9.678, de 3 de julho de 1998, dispositivo da Lei no 8.460, de 17 de setembro de 1992, a Tabela II do Anexo I da Medida Provisória no 2.215-10, de 31 de agosto de 2001, a Lei no 11.359, de 19 de outubro de 2006; e dá outras providências. Diário Oficial da União / Poder Executivo, 23 de setembro de 2008. Seção 1. Disponível em: < http://www.planalto.gov.br/ ccivil_03/_ato2007-2010/2008/lei/l11784.htm>. Acesso: 18 Jun. 2014.

BRASIL. Lei $\mathrm{n}^{0}$ 11.892, de 29 de dezembro de 2008b. Institui a Rede Federal de Educação Profissional, Científica e Tecnológica, cria os Institutos Federais de Educação, Ciência e Tecnologia, e dá outras providências. Diário Oficial da República Federativa do Brasil, Brasília, DF, 30 dez. 2008. Disponível em: <www.planalto.gov.br/ccivil_03/_ato20072010/2008/lei/l11892.htm>. Acesso em: 2 mar. 2013.

BRASIL. Ministério da Educação. Rede Federal de Educação Profissional, Científica e Tecnológica. Concepção e diretrizes - Institutos Federais de Educação e Tecnologia. 2010. Disponível em: < <http://portal.mec.gov.br/index. php?option $=$ com_docman\&view $=$ download \&alias $=6691-$ if-concepcaoediretrizes\&Itemid $=30192>>$. Acesso em: 25 fev. 2015 .

BRASIL. Tribunal de Contas da União (TCU). Secretaria Geral de Controle Externo Secretaria de Fiscalização e Avaliação de Programas de Governo. Relatório de auditoria operacional em ações da Rede Federal Profissional, Científica e Tecnológica. Brasília, jun. 2012. Disponível em: <http://portal.tcu.gov.br/lumis/ portal/file/fileDownload.jsp?inline $=1 \&$ fileId $=8$ A8182A14 D92792Co14D92847E5F3E97>. Acesso em: 12 abr. 2016.

BRASIL. Ministério da Educação. Secretaria de Educação Profissional e Tecnológica (SETEC). Relatório anual de análise dos indicadores de gestão das Instituições Federais de Educação Profissional, científica e tecnológica - Exercício 2014. jun. 2015. Disponível em: <http://portal.mec.gov.br/index.php?option=com_ docman\&view=download\&alias $=17929$-analise- 
indicadores-2014\&category_slug=julho-2015pdf\&Itemid=30192>. Acesso em: 12 abr. 2016.

BRESSER-PEREIRA, Luiz Carlos. Reforma do Estado e Administração Pública Gerencial. Revista do Serviço Público, Brasília, v. 1, n. 47, p. 7-40, jan. 1996. Disponível em: <http://www.bresserpereira.org.br/papers/1996/95. admpublicaburocraticaagerencial.pdf $>$. Acesso em: 20 out. 2014.

COLARES, André Felipe Vieira; SINDEAUX, Roney Versiani. Greve nas universidades federais em 2012: um movimento na academia e sua repercussão na sociedade. Textos \& Debates, Boa Vista, n. 24, p. 6177, 2013. Disponível em: <http://revista.ufrr.br/index.php/ textosedebates/article/view/1820>. Acesso em: 29 jun. 2015.

COSTA, Elen de Fátima Lago Barros. A criação e expansão dos institutos federais e a intensificação do trabalho do professor: uma análise preliminar. In: SEMINÁRIO NACIONAL UNIVERSITAS/BR, 3., 29-31 maio 2013, São Carlos. Anais... São Carlos: UFSCar, 2013. p. 1-18. Disponível em: <http:// www.diagramaeditorial.com.br/universitas/trabalhos/_ zpages/_trabalhos/eixo4/elen_de_fatima_lago_barros_ costa.pdf $>$. Acesso em: 8 ago. 2015.

DAL ROSSO, Sadi. Intensidade e imaterialidade do trabalho e saúde. Trabalho, Educação e Saúde, Rio de Janeiro, v. 4, n. 1, p. 65-91, 2006.

FRIGOTTO, Gaudêncio. A produtividade da escola improdutiva: um (re)exame das relação entre educação e estrutura econômico social capitalista. São Paulo: Cortez, 1984 .

HYPÓLITO, Álvaro Moreira. Estado gerencial, reestruturação educativa e gestão da educação. Revista Brasileira de Política e Administração da Educação, Porto Alegre, v. 24, n. 1, p. 63-78, jan./abr. 2008. Disponível em: <http://seer.ufrgs.br/rbpae/article/ view/19239/11165>. Acesso em: 29 nov. 2014.

INSTITUTO FEDERAL DE EDUCAÇÃO, CIÊNCIA E TECNOLOGIA DO PIAUÍ. Servidores do IFPI devem registrar frequência com ponto eletrônico. 25 mar. 2014. Disponível em: <http://www5.ifpi.edu.br/index. php?option $=$ com_content $\&$ view $=$ article\&id $=2720>$. Acesso em: 8 ago. 2015.

INSTITUTO FEDERAL DE EDUCAÇÃO, CIÊNCIA E TECNOLOGIA DO RIO GRANDE DO SUL - CÂMPUS RIO GRANDE. Sistema eletrônico de ponto começa nesta terça, $\mathbf{1}^{\circ}$, no Câmpus Rio Grande. mar. 2014. Disponível em: <http://www.riogrande.ifrs.edu.br/site/ conteudo.php? cat $=5 \& s u b=1674>$. Acesso em: 8 ago. 2015 . 
LIMA, Iana Gomes de; GANDIN, Luís Armando. Entendendo o estado gerencial e sua relação com a educação: algumas ferramentas de análise. Práxis Educativa, v. 7, n. 1, p. 69-84, 28 jun. 2012. Disponível em: <http://www. revistas2.uepg.br/index.php/praxiseducativa/article/ view/3398 >. Acesso em: 12 jan. 2016.

LIMA, Júlio César França; NEVES, Lúcia Maria Wanderley; PRONKO, Marcela Alejandra. Trabalho Complexo. In: PEREIRA, Isabel Brasil; LIMA, Júlio César França. Dicionário da educação profissional em saúde. 2. ed. rev. ampl. Rio de janeiro: EPJV, 2008. p. 415-419.

MARX, Karl. O Capital: crítica da economia política Livro I: o processo de produção do capital [tradução de Rubens Enderle]. 2. reimpr. São Paulo: Boitempo, jul. 2014.

MARX, Karl; ENGELS, Friedrich. A ideologia alemã. São Paulo: Editora Hucitec, 1987.

MAUÉS, Olgaíses Cabral; SEGENREICH, Stella Cecilia; OTRANTO, Celia Regina. As Políticas de Formação de Professores: a expansão comprometida. Revista Educação em Questão, v. 51, p. 42-72, 2015. Disponível em: http://www.periodicos.ufrn.br/educacaoemquestao/ article/view/7171/5297>. Acesso em: 10 abr. 2016.

NEVES, Lúcia Maria Wanderley; PRONKO, Marcela Alejandra. O mercado do conhecimento e o conhecimento para o mercado: da formação para o trabalho complexo no Brasil contemporâneo. Rio de Janeiro: EPSJV, 2008.

OLIVEIRA, Dalila Andrade. A Reestruturação do Trabalho Docente: precarização e flexibilização. Educação e Sociedade, Campinas, v. 25, n. 89, p. 1127-1144, 2004. Disponível em: <http://www.scielo.br/pdf/es/ v25n89/22614>. Acesso em: 9 set. 2015.

OTRANTO, Celia Regina. . A Política de Educação Profissional do Governo Lula: novos caminhos da Educação Superior. In: 34 a Reunião Anual da ANPED, 2011, Natal. Educação e Justiça Social. Natal: Editora da UFRN, 2011. v. 1. p. 122-139. Disponível em:<http://www. anped11.uerj.br/GT11-315\%2oint.pdf> Acesso em: 11 Fev. 2015

PINTO, Carmem Lúcia Lascano; GOES, Rosângela Irigaray Garcia de; KATREIN, Beatriz Helena; BARREIRO, Cristhianny Bento. Entre o Bem e o Mal-Estar: a intensificação do trabalho docente no âmbito dos Institutos Federais de Educação, Ciência e Tecnologia. Revista Educação por Escrito, v. 4, n. 1, p. 48-54, jul. 2013. Disponível em: <http://revistaseletronicas.pucrs.br/ojs/ 
index.php/porescrito/article/viewArticle/11219> Acesso em: 9 set. 2015 .

PINTO, Geraldo Augusto. A organização do Trabalho no século 2o: taylorismo, fordismo e toyotismo. 2. ed. São Paulo: Expressão popular, 2010.

PUZIOL, Jeinni Kelly Pereira; SILVA, Jani Alves da. A influência do capital humano e da teoria do capital social nas políticas educacionais brasileiras da atualidade. In: VI SEMINÁRIO DO TRABALHO: TRABALHO, ECONOMIA E EDUCAÇÃO, 28 a 30 de maio de 2008, Marília. Anais... Marília: UNESP, 2008. p. 1-16. Disponível em: <http:// www.unc.br/mestrado/textos/Bibliografia-2013-Infteoria-cap-humano-e-teoria-do-cap-social-nas-pol-educbras\%20.pdf >. Acesso em: 18 abr. 2015.

SANTOS, Márcia Luzia dos. Intensificação do trabalho docente: contradições da política de economizar professores. 2013. 239 f. Dissertação (Mestrado em Educação) - Programa de Pós-Graduação em Educação, Universidade Federal de Santa Catarina, Florianópolis, 2013.

SINDICATO NACIONAL DOS DOCENTES DAS INSTITUIÇÕES DE ENSINO SUPERIOR. ANDES-SN alerta para implantação ilegal de ponto eletrônico em IF. [s. d.]. Disponível em: <http://www.andes.org.br/ andes/portal.andes $>$. Acesso em: 6 out. 2015 .

SHIROMA, Eneida Oto. Mudança tecnológica, qualificação e políticas de gestão: a educação da força de trabalho no modelo japonês. 1993. 209 f. Tese (Doutorado em Educação) - Programa de PósGraduação em Educação, Universidade Estadual de Campinas, Campinas, 1993.

SHIROMA, Eneida Oto; LIMA FILHO, Domingos Leite. Trabalho docente na Educação Profissional e Tecnológica e no PROEJA. Educação \& Sociedade, v. 2, n. 116, p. 725-743, 2001.

SOUZA, Liliane Bordignon de. Reforma e expansão da educação profissional técnica de nível médio nos anos 2000. 2013. $201 \mathrm{f}$. Dissertação (Mestrado em Educação) - Programa de Pós-Graduação em Educação, Universidade Estadual de Campinas, Campinas, 2013.

STERING, Silvia Maria dos Santos; PEREIRA, Rupert Carlos de Toledo. Institutos Federais de Educação, Ciência e Tecnologia: a serviço de que ideologia essa Instituição desenvolve a formação profissional e tecnológica do trabalhador?. In: XIII COLÓQUIO INTERNACIONAL DE GESTIÓN UNIVERSITARIA EM AMÉRICA DEL SUR, 27 a 29 de novembro de, 2013, Buenos Aires. Anais... Buenos Aires: Facultad Regional Buenos Aires 
- FRBA, da Universidad Tecnológica Nacional - UTN, 2013. p. 1-26. Disponível em: <https://repositorio.ufsc. $\mathrm{br} / \mathrm{bitstream} / \mathrm{handle} / 123456789 / 114767 / 2013173 \% 20$ - \% 2 o Institutos \% 2 of ed e rais \% 2 o d e \% 2 o educa\% $3 \% \mathrm{C}_{3} \% \mathrm{C}_{3} \% \mathrm{~A} 30 . p d f$ ?sequence $=1$ \&isAllowed $=\mathrm{y}>$. Acesso em: 25 ago. 2015 .

TAVARES, Moacir Gubert. Institutos Federais e crise de identidade: O caso do IFC- Campus Rio do Sul. 2015. In: REUNIÃO NACIONAL DA ANPEd, 37., 4-8 out. 2015, Florianópolis. Anais... Florianópolis: UFSC, 2015. p. 1-20. Disponível em: <http://37reuniao.anped.org.br/ wp-content/uploads/2015/o2/Trabalho-GT11-4151.pdf $>$. Acesso em: 6 out. 2015 .

TRIBUNAL REGIONAL FEDERAL DA $4^{\mathrm{a}}$ REGIÃO. TRF4 mantém ponto eletrônico para professores do IFRS de Rio Grande (RS). 29 set. 2014. Disponível em: <http://www2.trf4.jus.br/trf4/controlador.php?acao $=$ noticia_visualizar\&id_noticia $=10446>$. Acesso em: 6 out. 2015 .

Recebido em: 01/12/2016 Aprovado em: 22/12/2016 